\title{
Digital necrosis caused by a snake bite
}

\author{
Hasan Kara*, Ahmet Ak, Ayşegül Bayır, Murat Akıncı, Hamide Alp, Selim Değirmenci \\ Department of Emergency Medicine, Faculty of Medicine, Selcuk University, Konya, Turkey
}

\section{ARTICLE INFO}

\section{Article History}

Received $\quad 02 / 09 / 2013$

Accepted $\quad 25 / 10 / 2013$

\section{* Correspondence to:}

Hasan Kara

Department of Emergency Medicine,

Faculty of Medicine,

Selcuk University,

Konya, Turkey

e-mail: hasankara42@gmail.com

\section{ABSTRACT}

Snake bite is a prevalent significant cause of morbidity and mortality especially in the rural areas during summer months. It can lead to local and systemic complications varying according to the contents of the toxin. The rapid reversible systemic effects of antivenom are coagulopathy and hemorrhage. Local effects are pain, edema, bulla, secondary infection, dermatonecrosis and necrosis. Although most snake bite lesions heal without any sequela, necrosis in the bitten area, acute renal failure, compartment syndrome, disseminated intravascular coagulation, intracranial hemorrhage and death might occur. While $90-98 \%$ of the snake bites are seen on the extremities, digital necrosis is not a common state. In this report, a digital necrosis developed in the patient who applied with the complaint of a snake bite on the fourth finger of her left hand has been pointed out.

J. Exp.Clin.Med., 2013; 30:377-379

\section{Keywords:}

Critical care

Digital necrosis

Snake bite

Venom

\section{Introduction}

Snake bite is a significant cause of morbidity and mortality with increasing frequency especially in the southeastern Anatolia region of Turkey during summer months due to its climate and geographic features. Snake bites are encountered more frequently in the lower extremities. The snake bites in the head and trunk region are two-three times more lifethreatening than the bites in the extremities. It can lead to local and systemic complications varying according to the contents of the toxin (Yuksel et al., 2009). The rapid reversible systemic effects of antivenom are coagulopathy and hemorrhage. Although most snake bite lesions heal without any sequela, necrosis in the bitten area, acute renal failure, compartment syndrome, disseminated intravascular coagulation, intracranial hemorrhage and death might occur. The most effective method against snake bites is the antiserum administration, and it is vital to apply it with the required dose as soon as possible prevent mortality and morbidity. While $90-98 \%$ of the snake bites are seen on the extremities, digital necrosis is not a common state.

\section{Case}

A seventy-one-year-old female patient was brought to the emergency service two hours after having been bitten by a snake with the complaint of a bite on the $4^{\text {th }}$ finger of her left hand while working in the chicken shed. At her arrival, arterial blood pressure was $140 / 80 \mathrm{mmHg}$, pulse: $88 / \mathrm{min}$ and temperature was: $37.0^{\circ} \mathrm{C}$. In the distal end of 4 th finger of the left hand and left upper extremity was there a diffuse edema, hyperemia and ecchymosis spots in patches (Fig. 1,2, 3 ). The other physical examination findings of the case were considered as normal and white blood cell was $10.6 \times 10^{3} / \mu 1$, platelet was $143 \times 10^{3} / \mu 1$ and international normalized ratio was 1.08 in the examination performed at the admission. A consultation was held with orthopedics, cardiovascular surgery and infectious diseases clinics and the thoughts of the related clinics were taken into consideration. Although orthopedic clinic suggested elective amputation of finger, the patient and her son who is a doctor refused the surgery. The patient was hospitalized in the intensive care unit with the diagnosis of digital necrosis caused by a snake bite in the 4th 
finger of the left hand. As a treatment, the patient was given intravenous fluids, low-molecular-weight heparin, antibiotic (ceftriaxone) and analgesic (tramadol and tenoksikam). The edema and ecchymosis decreased. When the patient recovered clinically on the sixth day of the follow-up, she was discharged on her own request with advices.

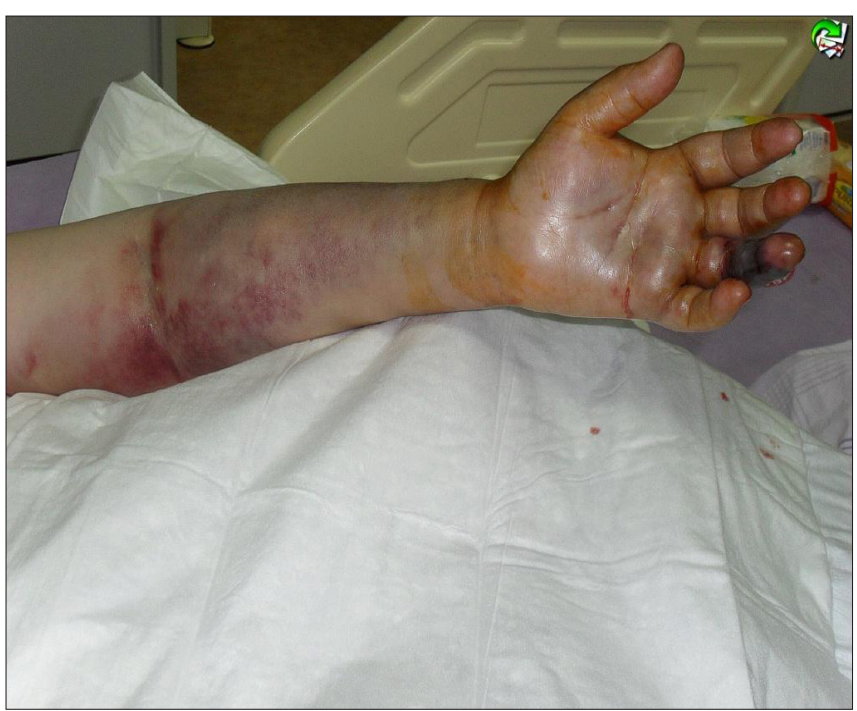

Fig. 1. Tense, swollen, edematous hand with digital necrosis.

\section{Discussion}

The snake bites in Turkey are important causes of mortality and morbidity due to climate features. Generally Viperidae group poisonous snakes exist in our country. The poison of these snakes not only leads to systemic intoxication such as intravascular coagulopathy but it may also cause ex tremity loss due to the effects of tissue necrosis (Açıkalın et al., 2008). The local effects of biting are pain, edema, erythema, sometimes local bleeding, ecchymoses, bulla, local lymphadenopathies and tissue necrosis. Shortly after being bitten, severe pain starts in the bitten area and edema and swelling occur there. Necrosis develops on and under the skin (Buyukbebeci et al., 2001; Chotenimitkhun and Rojnuckarin, 2008). Tissue necrosis can develop in about $10 \%$ of the snake bitten cases (Chippaux, 1982). In addition to the local necrosis caused by a snake bite, bulla and abscess formation can occur in the first 24 hours in the bitten region. When our case was examined in

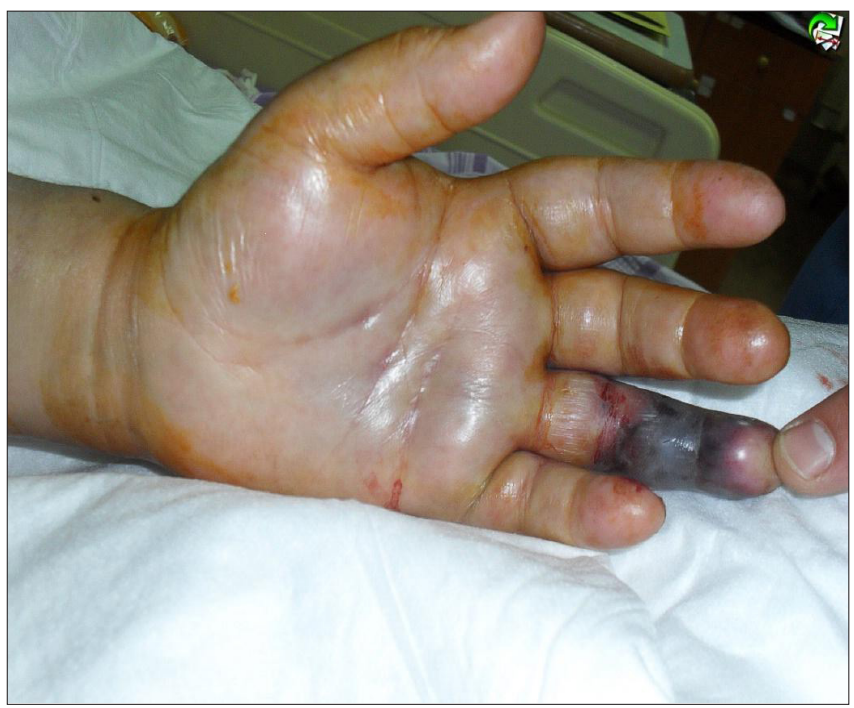

Fig. 2. A rewiev of the extremity from front side. the second hour, necrosis formation initiated in the distal of the bitten area, and hyperemia and ecchymoses existed in the periphery. Within a few hours, anesthesia caused by a snake bite starts in the bitten region or extremity and fasciculations may occur in the adjacent muscles. Death usually develops as a result of plasma loss and collapse caused by increased capillary membrane permeability. Death may be observed within 6-48 hours as a result of fever, nausea, vomiting, bleeding in the skin and internal organs, speech disorder, tachycardia, muscle spasms, myosis, secondary infection, acute renal failure, convulsions, respiratory and circulatory system failure (Kerrigan, 1991). Our case received the first intervention and underwent antivenin treatment at admission. When it was determined that the patient had local edema, erythema and digital necrosis, she was supported and treated under intensive care conditions. Although all the cases bitten by a snake undergo tetanus prophylaxis, it is controversial to administrate antiserum treatment except for the cases with local complications. The antibiotic to be chosen should affect gram-positive aerobic cocci and anaerobics (Ertem et al., 2005).

Hyperbaric $\mathrm{O}_{2}$ therapy can be effective in the cases with severe necrosis. Hemorrhagic bullae, superficial necrotic tissue can be debrided three-five days later. It is important to initiate physical therapy after the first debridement for the extremity to return of functional capacity. Compartment syndrome caused by snake bites rarely occurs. The delay in the diagnosis of compartment syndrome leads to amputation in ischemic contractures or limbs at different levels (McQueen et al., 2000; Firat et al., 2012). Since our case had fever and leukocytosis, broad-spectrum antibiotics were initiated. Local wound care was also performed. The case had local edema in the upper extremity; however compartment syndrome did not develop. The patient should be reassured about the first aid applications, try to soothe him/her, the wound surface should be cleaned without tampering the wound and the bitten extremity should be immobilized absolutely. As the snake venom usually spreads through lymphatic system, instead of constrictive bandage that can hinder arterial circulation, compression was performed with elastic bandages and the extremity was immobilized.

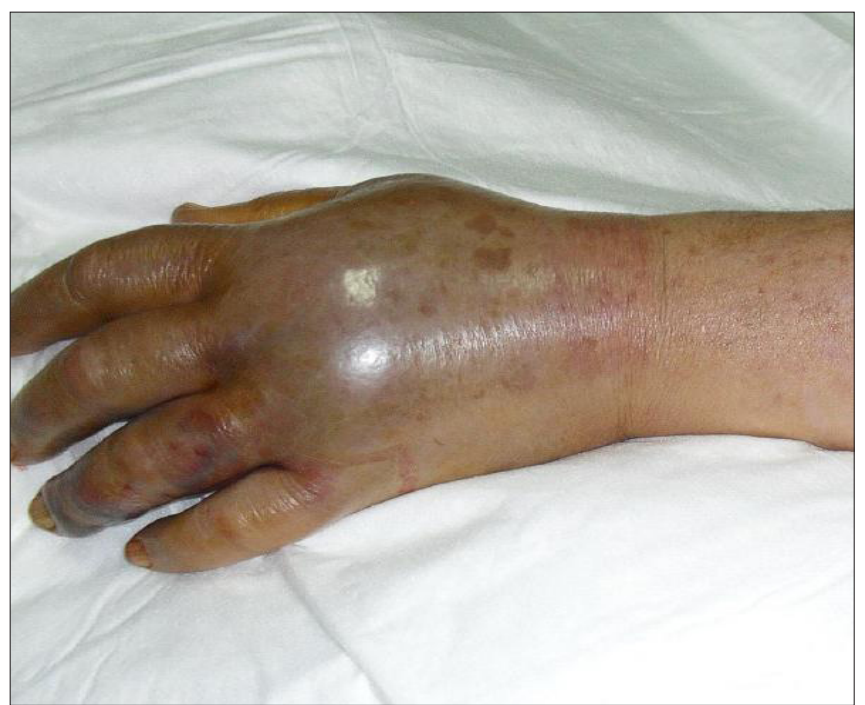

Fig. 3. A rewiev of the extremity from dorsal side. 


\section{Conclusion}

A patient, who states that she has been bitten by a snake, should be followed-up for at least two hours, the case without systemic or local symptoms should be evaluated and they should receive local injury treatment and undergo tetanus prophylaxis and antiserum treatment should be initiated without delay if required.

\section{REFERENCES}

Açıkalın, A., Gökel, Y, Kuvandık, G., Duru, M., Köseoğlu, Z., Satar, S., 2008. The efficacy of low-dose antivenom therapy on morbidity and mortality in snakebite cases. Am. J. Emerg. Med. 26, 402-407.

Büyükbebeci, O., Barlas, S.K., Karakurum, G., Güleç A., Demir S., 2001. Yılan sokmalarındaki klinik deneyimlerimiz. Arthroscopy. 12 , 47-49. Chippaux, J.P., 1982. Lokal complications of snake bites (author's transl). Med. Trop (Mars). 42, 177-183.

Chotenimitkhun, R., Rojnuckarin, P., 2008. Systemic antivenom and skin necrosis after green pit viper bites. Clin. Toxicol. 46, 122-125.

Ertem, K., Esenkaya, I., Kaygusuz, M.A., Turan, C., 2005. Our clinical experience in the treatment of snakebites. Acta. Orthop. Traumatol. Turc. 39, 54-58.

Fırat, C., Erbatur, S., Aytekin, A.H., Kılıç, H., 2012. Erken fasyotominin yılan ısırıkları tedavisindeki etkinligi. Ulus Travma Acil Cerrahi Derg. $18,417-423$.

Kerrigan, K.R., 1991. Venomous snakebite in eastern Ecuador. Am. J. Trop. Med. Hyg. 44, 93-99.

McQueen, M.M., Gaston, P., Court-Brown, C.M., 2000. Acute compartment syndrome. Who is at risk?. J. Bone Joint Surg. Br. 82, $200-203$.

Yuksel, A., Ergin, E., Barışık, V., 2009. Yılan sokması sonucu dissemine intravaskuler koagulasyon ve akut böbrek yetmezligi gelişimi. Fırat Üniversitesi Sağlık Bilimleri Tıp Dergisi. 23, 37-39. 